\title{
Transient Cutaneous Alterations of the Newborn
}

\author{
Authors: \\ Catarina Queirós, ${ }^{1}$ Mafalda Casinhas Santos, ${ }^{2}$ Rita Pimenta, ${ }^{1}$ Cristina \\ Tapadinhas, ${ }^{1}$ Paulo Filipe ${ }^{1,3}$ \\ 1. Serviço de Dermatologia, Hospital de Santa Maria, Centro Hospitalar e Universitário \\ de Lisboa Norte, Lisbon, Portugal \\ 2. Serviço de Pediatria, Hospital de Vila Franca de Xira, Lisbon, Portugal \\ 3. Faculdade de Medicina da Universidade de Lisboa, Lisbon, Portugal \\ *Correspondence to catarina.squeiros@gmail.com \\ Disclosure: $\quad$ The authors have declared no conflicts of interest. \\ Received: \\ 27.06.20 \\ Accepted: \\ 17.12 .20 \\ Keywords: \\ Common rashes, cutaneous alterations, newborn, skin. \\ Citation: \\ EMJ. 2021;6[1]:97-106
}

\begin{abstract}
Neonatal cutaneous alterations are common, usually appearing at birth or during the first few days of life. Most of these conditions are physiological, benign, and transient, arising from a combination of immaturity of the newborn skin with environmental factors. Nonetheless, some of them may eventually be a clue to underlying disorders. Physicians should therefore be aware of these clinical manifestations so that parents can be reassured and, when necessary, complementary investigations can be undertaken.
\end{abstract}

\section{INTRODUCTION}

At birth, the skin of the newborn suddenly comes into contact with the extrauterine world: a dry and aerobic environment. ${ }^{1}$ Newborn skin is 40-60\% thicker than adult skin, with weaker intercellular attachment and decreased production of sweat. ${ }^{2}$ Newborn skin is therefore more vulnerable, although structurally similar to adult skin, and trauma associated with delivery leaves its marks on it. ${ }^{3}$ Moreover, newborn skin must rapidly adapt and mature to provide protection against infection, toxins, changes in temperature, and transepidermal water loss, which poses an additional stress. ${ }^{1}$

Because of these factors, cutaneous alterations are relatively common in the neonatal period. ${ }^{3}$ Most of these conditions are physiological, benign, and transient, thus do not require therapy. ${ }^{4}$ Nevertheless, they are frequently a cause of concern to parents, who need reassurance about its nature.

In this paper, several common cutaneous alterations observed in newborn skin are reviewed. In the first part, physiological changes are covered, including traumatic, vascular, pigmentary, and hormonal conditions. In the second part, a review of the most common rashes of the newborn is undertaken. Although not typically apparent during the neonatal period, infantile acropustulosis and eosinophilic pustular folliculitis are included as these are important in the differential diagnosis of other conditions.

\section{PHYSIOLOGICAL ALTERATIONS}

\section{Vernix Caseosa}

The vernix caseosa is a protective layer which covers neonatal skin at birth (Figure 1). It is a 
complex membranous substance comprising $80 \%$ water, $10 \%$ protein, and $10 \%$ lipids, which include barrier lipids such as ceramides, free fatty acids, phospholipids, and cholesterol, partly synthesised by fetal sebaceous glands during the last trimester of pregnancy. ${ }^{5}$ In its composition there are also shed lanugo hair and desquamated cells. In utero, the vernix protects neonatal skin against amniotic fluid. ' During transition to an extrauterine environment, the vernix has several important functions including lubrication of the birth canal during parturition, prevention of water loss, and temperature regulation. It is also implicated in the development of innate immunity and facilitates reduction of skin $\mathrm{pH}$ to the ideal range for optimal skin function; 1,5 therefore, the vernix should be left as undisturbed as possible. Gentle bathing or dry wiping does not significantly disrupt this layer, and should therefore be the procedures of choice for newborns' hygiene.

\section{TRAUMATIC LESIONS}

\section{Sucking Blisters}

Sucking blisters are estimated to occur in 1:250 live births and result from vigorous sucking by the infant during fetal life. Clinically, flaccid bullae on a noninflamed base are seen, which rupture easily, leading to linear or round erosions. Lesions are present at birth and are located mainly on the forearm, wrist, and hand. Although frequently solitary, blisters can be multiple and bilateral. ${ }^{6}$ Diagnosis of congenital sucking blisters is one of exclusion. The absence of lesions in other body regions, the timing of onset, and the rapid resolution of the blisters, in combination with the otherwise well appearance of the neonate, are highly suggestive of this condition. ${ }^{7}$ Differential diagnosis of sucking blisters includes congenital or neonatal herpes simplex virus infection, fetal or neonatal varicella, bullous impetigo, epidermolysis bullosa, congenital syphilis, or congenital candidiasis, among other rarer entities. ${ }^{6}$ Sucking blisters resolve spontaneously in days to weeks without sequelae, and therefore no specific therapy is needed. ${ }^{6}$

\section{Caput Succedaneum and Cephalohaematoma}

Caput succedaneum refers to a collection of oedematous fluid above the periosteum, between the outermost layer of the scalp and the subcutaneous tissue. It is a common lesion seen at birth, and results from the high pressure exerted on the infant's head by the vaginal walls and uterus as the head passes through the narrowed cervix during labour. ${ }^{8}$

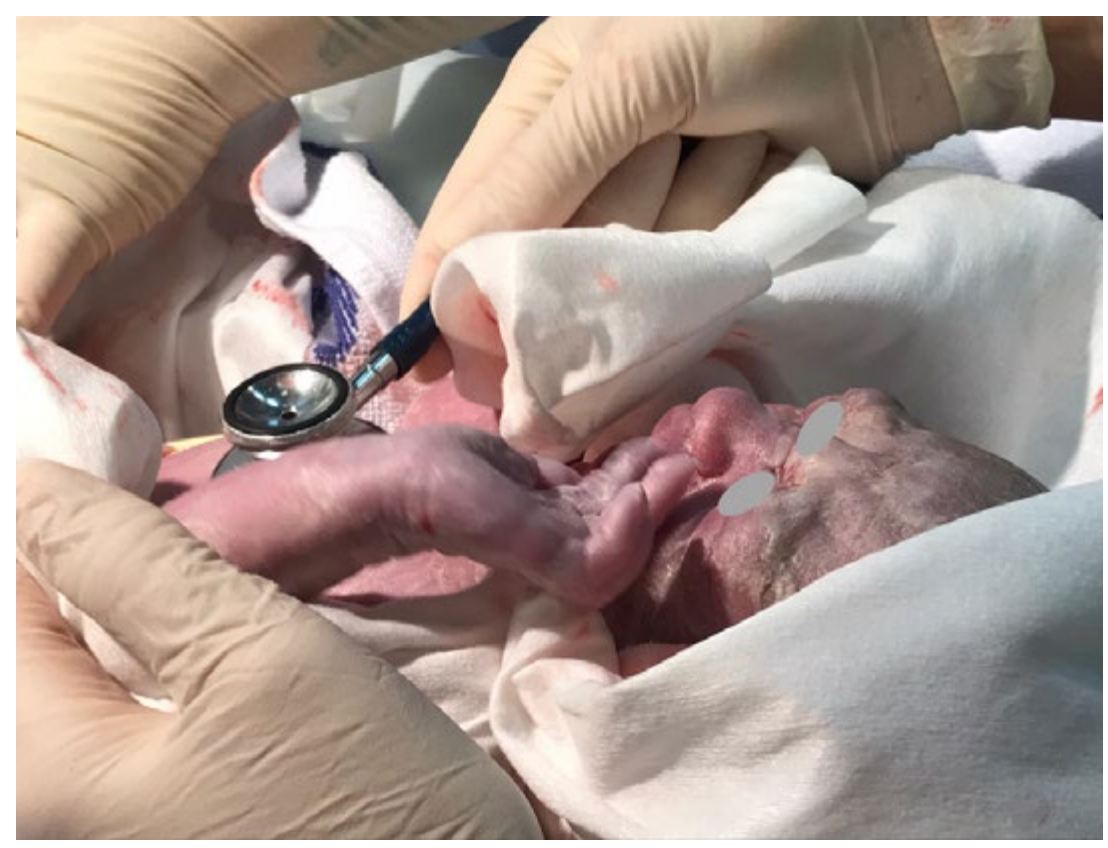

Figure 1: Vernix caseosa covering the skin of a newborn. 
Although caput succedaneum may occur in the absence of risk factors, incidence increases in difficult or prolonged labours, with premature rupture of the amniotic membranes, in primigravidae, and in instrument-assisted deliveries. This condition is evident immediately after delivery and gradually decreases in size thereafter. ${ }^{9}$ On physical examination, it is generally $1-2 \mathrm{~cm}$ in depth and has a soft, boggy feel with irregular margins. Petechiae, purpura, and an ecchymotic appearance may be present. ${ }^{8}$

Cephalohaematoma is a subperiosteal accumulation of blood, which occurs infrequently, with an incidence of $0.4-2.5 \%$ of all live births. It is more common in primigravidae, in infants with higher percentiles, and following instrument-assisted deliveries or prolonged, difficult labour and, for unknown reasons, occurs twice as often in males as in females. Because of the slow nature of subperiostial bleeding, cephalohaematomas are not usually present at birth but develop hours or even days after delivery. ${ }^{9}$ As the bleeding continues and blood occupies the subperiosteal space, pressure acts as a tamponade to stop further bleeding. A firm, enlarged unilateral or bilateral bump covering one or more bones of the scalp characterises this lesion. Unlike caput succedaneum, cephalohaematomas do not cross suture lines. ${ }^{8}$

Cephalohaematoma and capput succedaneum must be distinguished from subgaleal haematomas, which, unlike the former conditions, can be life-threatening. Neonatal subgaleal haematomas are usually associated with vacuum extraction deliveries, although they have also been reported in deliveries without instrument use. $^{10}$ Observation is the primary treatment for both uncomplicated caput succedaneum and cephalohaematoma. Resolution of caput succedaneum is generally spontaneous and occurs within the first few days following birth. A cephalohaematoma may take longer to resolve, but most cases do so within 2 to 6 weeks of life. ${ }^{8}$

\section{VASCULAR PHENOMENON}

\section{Acrocyanosis}

Acrocyanosis is often seen in healthy newborns during the first hours of life and refers to the occurrence of peripheral cyanosis around the mouth and the extremities. It is caused by benign vasomotor changes that result in peripheral vasoconstriction and increased tissue oxygen extraction, attributed to peripheral arteriole hypertonia. Acrocyanosis is a benign condition and may persist for 24 to 48 hours. After this period, it may occasionally recur in the context of cold exposure or crying." Acrocyanosis must be distinguished from central cyanosis. This is defined as a dusky appearance of the body and the mucous membranes and is always concerning beyond the first 10 minutes of life. Abnormalities in ventilation, congenital heart abnormalities, and haemoglobinopathies are amongst the main causes of central cyanosis. ${ }^{11}$

\section{Cutis Marmorata}

Cutis marmorata is a benign entity characterised by the appearance of a reticulated or livedoid purplish mottling of the skin, related to physiological capillary and venular vasomotion in the setting of cold exposure. ${ }^{12}$ Cutis marmorata seems to be associated with lower gestational age and birth weight, which may be associated with the greater vulnerability of these neonates, who are therefore more likely to present with vasomotor instability. ${ }^{3}$ This condition must be distinguished from cutis marmorata telangiectatica congenita, which is characterised by a fixed vascular change associated with subtle dermal atrophy. This entity may be associated with limb length discrepancy, vascular, osseous, ocular, and neurologic malformations. ${ }^{12}$

\section{Harlequin Colour Change}

Harlequin colour change presents as erythema in one half (the dependent side) and pallor in the other half of the body, usually lasting for several minutes. This condition presents in the first 3 weeks of life, commonly between Day 2 and Day 5.11,12 Although it has been observed in neonates after the administration of anaesthetic agents and alprostadil, harlequin colour change may also occur in healthy neonates in the absence of medication. This phenomenon may occur as a result of changes in vascular tone, although it still remains unexplained. Harlequin color change is a benign and transient feature; therefore, no treatment is necessary. ${ }^{13}$ 


\section{Salmon Patch}

Salmon patch, also known as naevus flammeus, naevus simplex, or unna naevus, is a common congenital capillary malformation that is usually found in the midline. ${ }^{14}$ It affects approximately $50 \%$ of newborns and is more frequent in those born with greater weight, at term or post-term. A slight female predominance has been observed.15 Salmon patches arise from dilations of capillaries within the dermis, which may result from persistent fetal circulation in newborns. ${ }^{4}$ Clinically, they present as pink or red irregular macules, which may become confluent (Figure 2A).

Lesions tend to bleach with digital pressure, and are more apparent with crying, apnoeas, fever, and changes in ambient temperature. Salmon patches occurr most frequently on the nape of the neck, the eyelids, and the glabella, and are usually transitory, disappearing during the first 2 years of life. Nearly one-half of those located in the nape of the neck and in the sacral region, and a small percentage of those located in the glabellar zone, may persist. ${ }^{14,15}$ Salmon patches need to be distinguished from cutaneous capillary malformation, formerly referred to as 'port wine stain', a potential marker of SturgeWeber syndrome. The variant 'en coup de sabre' of congenital morphea is another differential diagnosis of this condition.

\section{PIGMENTARY CHANGES}

\section{Mongolian Spot}

Mongolian spot (MS) is a type of dermal melanocytosis, which presents at birth or soon thereafter as an ill-defined area of slate gray to blue/black pigmentation, usually over the sacrococcygeal or lumbar area. Both sexes are equally affected, and these lesions are more common in newborns of Asian and/or African descent. ${ }^{16,17}$ MS arise from a defect in melanocyte migration. Melanocytes are present in dermis of the embryos at the beginning of the $10^{\text {th }}$ week of gestation, and they migrate to the epidermis between the $11^{\text {th }}$ and the $14^{\text {th }}$ week. After Week 20, no melanocytes are found in the dermis. Failure of this migration results in the appearance of $\mathrm{MS}^{16}$ Clinically, MS are round, oval, or irregular macules. The colour varies from blue to green, grey, black, or a combination of any of these colours. Lesions may be single or multiple, and their size ranges from $<1 \mathrm{~cm}$ to $>20 \mathrm{~cm}$. Pigmentation is more intense at the age of 1 year and gradually fades thereafter. ${ }^{16,17}$ MS must be differentiated from other dermal melanocytoses like naevus of Ota, naevus of Ito, Hori naevus, and blue naevus.

Onset at birth, disappearance with age, absence of mucosal involvement, and no progression to malignancy favour the diagnosis of MS.

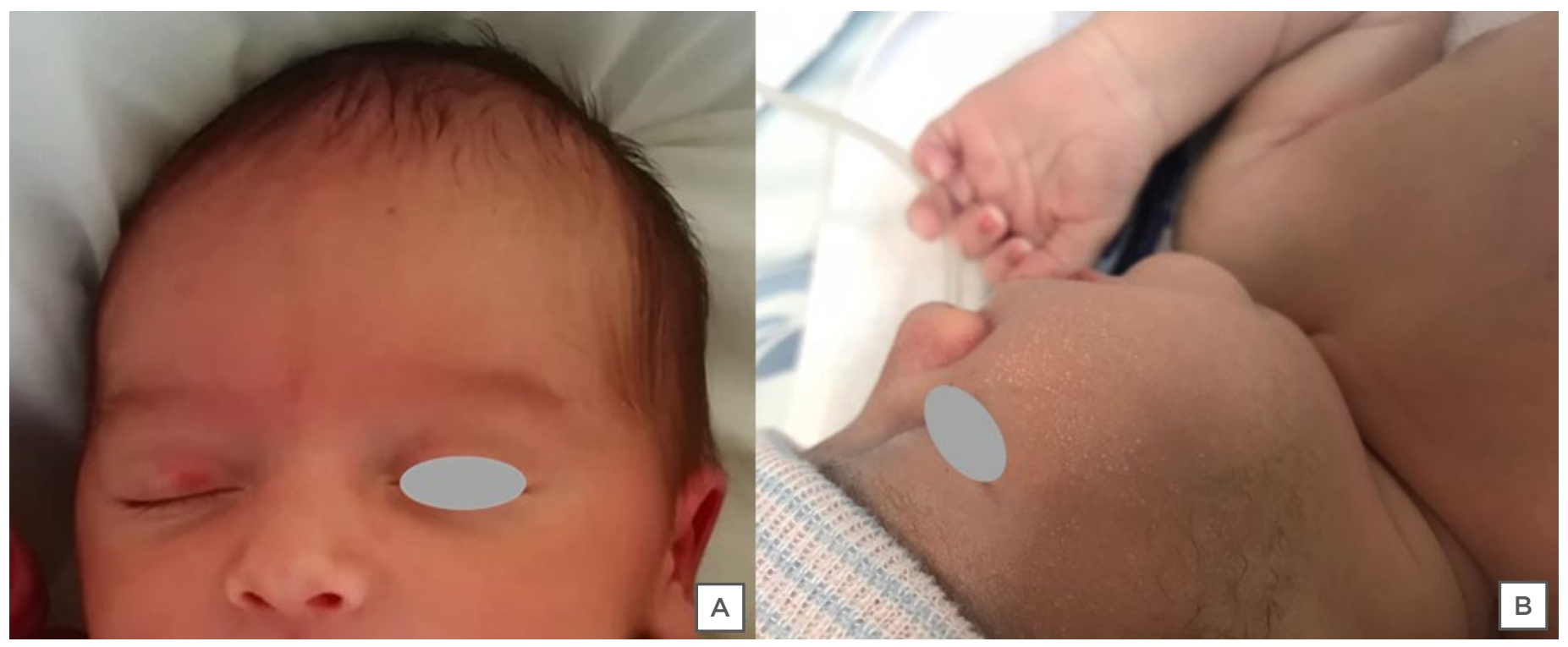

Figure 2: Physiological alterations. A) Salmon patch in the upper eyelid of a 1-week-old female. B) Milia cysts overlying the cheek of a 2-week-old newborn. 
MS usually resolve by early childhood, hence, no treatment is needed if they are located in the sacral area; nonetheless, it may be required for extrasacral lesions due to cosmetic issues. ${ }^{16}$ Although most MS are benign lesions, recent data suggested that MS may be associated with inborn errors of metabolism such as lysosomal storage diseases. Therefore, extrasacral, extensive, persistent, and dark-coloured spots should be looked upon with suspicion, especially in the presence of a consanguineous marriage or a strong family history of storage disorders. ${ }^{4}$

\section{Epidermal Hyperpigmentation}

Epidermal pigmentary changes are also common in newborns and include linea nigra and hyperpigmentation of the knuckles, genital, axilla, or areolar regions. Hyperpigmentation of the skin over the distal phalanges has also been described, particularly in newborns with higher phototypes. ${ }^{18}$ This abnormal pigmentation is transient and probably represents a response to maternal and placental hormones that enter the newborn circulation. Among these hormones, oestrogen and progesterone have been reported to exert a melanocytic stimulating effect, which is also responsible for the darkening of linea alba in pregnant females. As these are transient and benign changes, no treatment is necessary. ${ }^{2}$ Abnormal hyperpigmentation may be a sign of congenital adrenal hyperplasia; however, in this condition, there are usually associated findings such as virilised external genitalia.

\section{HORMONAL CHANGES}

Sebaceous gland hyperplasia is a common physiological phenomenon in newborns, affecting mainly full-term infants..$^{19,20}$ It is caused by high sebum secretion rates reflecting the stimulation by placentally transferred maternal androgens, particularly dehydroepiandrosterone. ${ }^{2,19}$ Clinically, sebaceous hyperplasia is characterised by multiple, yellow to flesh-coloured tiny papules on the nose, cheeks, and chin, where the density of sebaceous glands is highest. ${ }^{19,20}$ Sometimes the papules can coalesce into plaques without surrounding erythema. The most important differential diagnosis of this condition are milia cysts, which are epidermal inclusion cysts, usually solitary and whiter in colour. ${ }^{20}$ Sebaceous gland hyperplasia spontaneously resolves within the first few weeks of life, and therefore no treatment is required. ${ }^{19,20}$

\section{OTHER PHYSIOLOGICAL LESIONS}

\section{Epstein Pearls and Bohn's Nodules}

Epstein pearls occur in $64-89 \%$ of neonates and are more common in newborns of Caucasian descent. These lesions, also known as palatal microkeratocysts of the newborn, are whiteyellow cysts usually $1-3 \mathrm{~mm}$ in size. They are typically seen on the median palatal mouth raphe and represent epithelial tissue trapped during the palatal fusion. ${ }^{20}$ Similar cysts on the alveolar ridges or in the periphery of the palate are called Bohn's nodules. These are keratin cysts derived from the dental lamina, and they do not require treatment as they spontaneously resolve over the first few months of life. ${ }^{20}$

\section{Milia Cysts}

Milia cysts are small lesions resulting from retention of keratin within the dermis. They affect approximately $40-50 \%$ of newborns and may be present at birth or appear later in infancy..$^{19}$ Milia cysts appear as tiny, white, or yellow smooth-surfaced papules 1-2 $\mathrm{mm}$ in diameter, most commonly located over the cheeks, forehead, nose, and nasolabial folds (Figure 2B). ${ }^{19,20}$ Lesions may be few or numerous and are frequently grouped, with a tendency towards disappearance during the first 3 to 4 weeks of life. The most important differential diagnosis of milia cysts is sebaceous hyperplasia, which tends to be slightly more yellow. ${ }^{20}$ No therapy is required, as lesions tend to spontaneously resolve. However, it is important to note that persistent and widespread milia may be a feature of associated syndromes such as basal naevus syndrome, Rombo syndrome, Brooke-Spiegler syndrome, or pachyonychia congenita Type II, and therefore complementary investigation should be conducted in these particular settings.

\section{Koilonychia}

Koilonychia refers to nails with a transverse and/ or longitudinal concave central depression. It can be hereditary, acquired, or idiopathic. In newborns, it is frequently idiopathic, affecting particularly the hallux. In these circumstances, koilonychia tends to spontaneously regress 
with growth. ${ }^{21}$ Nonetheless, it is important to remember that these nail changes, later in life, may also be a manifestation of inflammatory skin diseases such as psoriasis, lichen planus, or secondary to systemic alterations, such as iron deficiency or endocrine disorders. ${ }^{22}$

\section{Traumatic Punctate Leukonychia}

Punctate leukonychia is a true leukonychia caused by alterations or imperfections in the proximal nail matrix. ${ }^{21}$ As the nail plate has a very smooth surface in newborns, these lesions can be easily observed. ${ }^{23}$ No specific treatment is required, as they tend to resolve with nail growth. ${ }^{21}$

\section{Beau's Lines}

Beau's lines of the fingernails appear at 4 weeks of life in $92 \%$ of newborns and disappear with growth, usually before 14 weeks. ${ }^{21}$ They result from intrauterine distress or physiological alterations during birth that cause mild trauma to the proximal nail matrix, with transiently reduced nail growth. ${ }^{23}$ Clinically, one can observe linear transverse nail plate surface depressions, which require no particular approach. ${ }^{21}$

\section{COMMON RASHES}

\section{Erythema Toxicum Neonatorum}

Erythema toxicum neonatorum (ETN) is a common condition, affecting neonates of all races and ethnicities worldwide. Its incidence ranges from as low as $3.7 \%$ to as high as $72 \%$, affecting predominantly full-term neonates weighing over 2,500 g. 3,24,25 Although the pathogenesis of this condition is unknown, recent studies suggest that ETN may represent a cutaneous immune reaction to an acute, transitory attack of the commensal microflora that penetrate the newborn skin via hair follicles, a condition which presupposes a certain degree of maturity of the immune system. ${ }^{3,24}$

ETN is a self-limited condition, usually beginning within the first 2 days of life and resolving entirely within 6 days. Recurrence occurs in up to $11 \%$ of neonates, usually between 5 and 11 days after the original eruption. ${ }^{24}$ This transient neonatal rash is asymptomatic and resolves without sequelae, with individual lesions rarely persisting for more than 1 day. ${ }^{25}$ Five distinct components may be present in various combinations, which include erythematous macules, wheals, papules, small pustules, and vesicles, usually measuring 1-2 mm. The eruption usually occurs throughout the body, typically involving the trunk, face, buttocks, and thighs; the palms, soles, and genitals are spared. ${ }^{24}$

Diagnosis of ETN is usually clinical. A cytologic exam of pustule contents shows more than $50 \%$ eosinophils, with or without a small number of neutrophils. Peripheral blood eosinophilia up to $15 \%$ may frequently coexist. Histopathologic examination is rarely necessary, but when performed it shows superficial dermal oedema with a mild diffuse and perivascular eosinophilic infiltrate. Pustules are subcorneal or intraepidermal and are associated with the pilosebaceous orifice in most cases. ${ }^{24}$ The differential diagnoses of ETN include sepsis, staphylococcal folliculitis, miliaria, congenital candidiasis, acne neonatorum, transient neonatal pustular melanosis, infantile acropustulosis, neonatal varicella, and occasionally incontinentia pigmenti. ${ }^{24}$

It is important to educate parents about the transient nature of this eruption. Although antihistamines may alter the duration of ETN, their use is not necessary as the rash does not seem to bother the child. The most useful therapy remains reassurance that the eruption is benign and will resolve without sequelae. ${ }^{24}$

\section{Transient Neonatal Pustular Melanosis}

Transient neonatal pustular melanosis (TNPM) is a benign condition most commonly affecting infants who are black. It affects both sexes with the same frequency and lesions are virtually always present at birth. ${ }^{26}$ So far, the aetiology of TNPM remains unknown. Some authors consider it a variant of ETN, although this has not been confirmed. ${ }^{27}$

TNPM features three different morphologies, which can coexist or occur sequentially. At delivery, flaccid and superficial noninflammatory vesicopustules are usually present in the chin, forehead, nape of the neck, lower back, buttocks, and shins. These lesions are easily disrupted, leaving hyperpigmented macules with fine collarettes of scale. Finally, residual hyperpigmented macules may persist for several months. ${ }^{27}$ 
Diagnosis of TNPM is generally clinical. Cytological examination of the pustules shows polymorphonuclear neutrophils. Histological examination is rarely permorfed, but will show intra- or subcorneal pustules containing primarily neutrophils. Pigmented macules show increased melanin in basal keratinocytes. Differential diagnosis of this condition is similar to that of ETN. ${ }^{26,27}$ As in ETN, no treatment is necessary for this condition. Parents' reassurance of its benign and self-limited nature is all that is needed. ${ }^{27}$

\section{Miliaria}

Miliaria is a common condition affecting up to $15 \%$ of newborns, and is commonly observed in summer months, febrile periods, or in newborns with excess clothing. ${ }^{27}$ The most common type of miliaria in the immediate neonatal period is miliaria crystallina (MC), which is characterised by small, clear, and flaccid vesicles over healthy skin, especially on the face, neck, trunk, and occluded areas. MC is caused by obstruction of the eccrine sweat duct as it courses through the stratum corneum. ${ }^{28}$

Miliaria rubra (MR) is another type of miliaria, also caused by obstruction of eccrine sweat gland ducts but deeper within the spinous layer. Leakage of fluid into the lower epidermis and superficial dermis leads to local inflammation, characterised by numerous erythematous papules, vesicles, and pustules (Figure 3A). ${ }^{28} \mathrm{MR}$ lesions usually begin after the $2^{\text {nd }}$ week of life and predominate in the trunk and intertriginous areas, where occlusion by clothing is accentuated. In hot environments, lesions on the scalp, face, and neck area may appear. ${ }^{27}$ Rarely, MR can progress to miliaria profunda, where the obstruction of the eccrine gland duct is even deeper. ${ }^{27}$ This type of miliaria is very rare in infants, usually occurring in older patients in tropical climates.

Diagnosis of miliaria is clinical. Cytologic examination of vesicopustule material shows a predominance of lymphocytes. Histologically, in MC, subcorneal or intracorneal vesicles centered on the acrosyryngium are seen, with little surrounding inflammation. In MR, intraepidermal spongiosis and vesicles are found, along with a chronic inflammatory infiltrate in the dermis. ${ }^{27}$ Lesions of milaria resolve without intervention, but there is a proven benefit in lowering the environment temperature. Prevention may be accomplished by avoiding overheating and excessive swaddling. ${ }^{27}$

\section{Neonatal Cephalic Pustulosis}

Neonatal cephalic pustulosis (NCP) is a relatively common benign condition with prevalence estimated between $10 \%$ and $66 \%{ }^{25}$ It usually develops within the first 2-3 weeks of life, and is characterised by multiple inflammatory papules and pustules mainly on the cheeks but also on the forehead, chin, neck, upper chest, and scalp (Figure 3B). ${ }^{27}$ Although an inflammatory response to Malassezia spp. has been suggested to be involved in the pathogenesis of NCP, this has not been confirmed. ${ }^{29}$ Diagnosis of NCP is usually clinical. A Giemsa-stained smear of pustular contents can show yeast forms, neutrophils, and inflammatory cells. ${ }^{27}$ Although topical imidazole or hydrocortisone are sometimes prescribed, no treatment is needed for this condition as it has a self-limited course with spontaneous involution over weeks to months.

\section{Neonatal Acne}

Neonatal acne occurs in up to $20 \%$ of newborns. This condition may be evident at birth or appear during the first 4 weeks of life and is more commonly seen in males. ${ }^{30}$ Several factors may contribute to the development of neonatal acne, including increased sebum excretion, stimulation of the sebaceous glands by maternal or neonatal androgens, and colonisation of sebaceous glands by Malassezia species. ${ }^{31}$ Neonatal acne typically presents as small, closed comedones on the forehead, nose, and cheeks. Accompanying sebaceous hyperplasia is often noted. Less frequently, open comedones, inflammatory papules, and pustules may also develop. Several eruptions should be considered in the differential diagnosis of neonatal acne, including erythema toxicum neonatorum, transient neonatal pustular melanosis, milia, and pustular miliaria. Other entities to be considered include bacterial folliculitis, secondary syphilis, herpes simplex virus and varicella zoster virus, and skin colonisation by fungi of Malassezia species. Drug eruptions associated with hydantoin, lithium, or halogens should be considered in particular cases. $^{30}$ Neonatal acne is usually mild and selflimited, resolving spontaneously without scarring in approximately 1-3 months. ${ }^{31}$ 


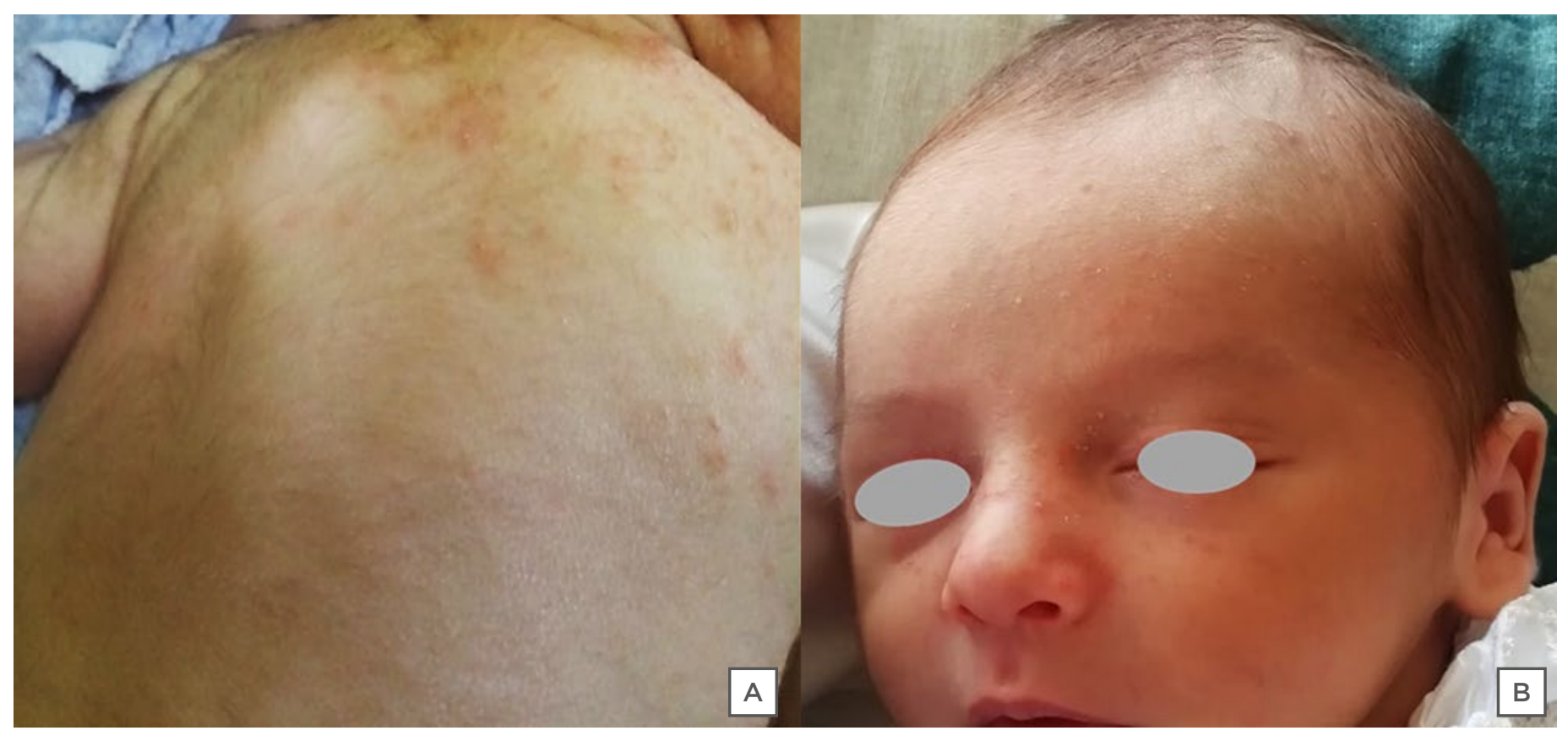

Figure 3: Common rashes. A) Miliaria rubra lesions on the back of a 2-week-old male. B) Neonatal cephalic pustulosis on the face of a 3-week-old female.

Therefore, in most cases no treatment is needed except for reassurance. If necessary, comedones may be treated with azelaic acid cream $20 \%$ or tretinoin cream $0.025-0.050 \%$. For inflammatory lesions, erythromycin solution $2.0 \%$ and benzoyl peroxide gel $2.5 \%$ may be used. Severe or recalcitrant disease warrants a workup for congenital adrenal hyperplasia, a virilising tumour, or underlying endocrinopathy. ${ }^{30}$

\section{Infantile Acropustulosis}

Infantile acropustulosis (IA) is an uncommon condition, usually developing at approximately 3-6 months of age, although it can begin earlier. It is more common in males and in infants of African descent. ${ }^{25}$ Clinically, IA is characterised by recurrent crops of pruritic vesicopustules predominantly in the palms and soles, although it can also affect the back of the hands, feet, ankles, wrists, and scalp. Eruptions usually last between 7 and 14 days, recurring every 3-5 weeks. With time, episodes usually decrease in frequency and severity, eventually resolving completely by 3 years of age. ${ }^{32}$

Diagnosis of IA is clinical. Cytological examination of pustular contents shows a predominance of neutrophils, with occasional eosinophils. Histopathological examination, albeit rarely perfomed, demonstrates the presence of subcorneal pustules filled primarily with neutrophils. Scabies is the main differential diagnosis of this condition, and can usually be excluded by skin scraping examination. Incontinentia pigmenti is another condition in the differential diagnosis of IA. Other clinically similar conditions, such as dyshidrotic eczema and palmoplantar pustulosis, are rare in infants. Treatment of IA is symptomatic, usually requiring potent or superpotent topical corticosteroids and oral antihistamines. ${ }^{32}$

\section{Eosinophilic Pustular Folliculitis}

Eosinophilic pustular folliculitis (EPF) usually affects infants between 5 and 10 months of life, with a male to female ratio of $4: 1.33$ EPF is a polymorphous eruption characterised by recurrent eruptions of pruritic papules, pustules, and vesicles. Pruritic vesicopustules may coalesce, forming exudative and crusted plates located mainly on the scalp, and less commonly on the face and extremities. Eruptions are intermittent and self-limited, lasting from 1 to 4 weeks, and eventually resolving by 3 years of age.

Cytological examination of pustular contents reveals primarily eosinophils, without bacteria or other microorganisms. Histological examinations 
show a dense eosinophilic infiltrate with a predominant perifollicular distribution. Peripheral eosinophilia is observed in approximately $70 \%$ of cases. ${ }^{34}$

Differential diagnoses of EPF predominantly include ETN, TNPM, IA, bacterial folliculitis, tinea capitis. and reactions to arthropod bites. Other rarer conditions, such as Langerhans' cell histiocytosis and the vesicular-papulo-pustular eruption associated with autosomal dominant hyper-IgE syndrome, should be considered in the appropriate clinical settings. Treatment is primarily symptomatic and similar to that of IA, including midpotency topical corticosteroids, topical tacrolimus, and oral antihistamines. ${ }^{33}$ In more recalcitrant cases, oral dapsone and other oral antibiotics may be needed. ${ }^{34}$

\section{CONCLUSION}

Neonatal cutaneous alterations are common, usually appearing at birth or during the first few days of life. Most of these conditions are physiological and arise from a combination of immaturity of the newborn skin with environmental factors. Although the majority of these conditions are benign and sponteously reversible, some of them may eventually be a clue to underlying disorders. Physicians should therefore be aware of these clinical manifestations, so that parents can be reassured and, when necessary, complementary investigations undertaken.

\section{References}

1. Johnson E, Hunt R. Infant skin care: updates and recommendations. Curr Opin Pedi-atr. 2019;31(4):476-81.

2. Haveri F, Inamadar A. A crosssectional prospective study of cutaneous lesions in newborn. ISRN Dermatol. 2014;360590.

3. Ábrahám R et al. Cutaneous lesions and disorders in healthy neonates and their relationships with maternalneonatal factors: a cross-sectional study. World J Pediatr. 2017;13(6):5716.

4. Techasatian L et al. Neonatal birthmarks: a prospective survey in 1000 neonates. Glob Pediatr Heal. 2019;6:2333794X19835668.

5. Nishijima $\mathrm{K}$ et al. Biology of the vernix caseosa: a review. J Obs Gynaecol Res. 2019;45(11):2145-9.

6. Afsar $\mathrm{F}$ et al. Neonatal sucking blister. Dermatol Online J. 2019;25(11):pii: 13030/qt33b1w59j.

7. Adam R, Schroten H. Picture of the month. Congenital sucking blisters. Arch Pediatr Adolesc Med. 2007;161(6):607-8

8. Nicholson L. Caput succedaneum and cephalohematoma: the cs that leave bumps on the head. Neonatal Netw. 2007;26(5):277-81.

9. Petrikovsky BM et al. Cephalhematoma and caput succedaneum: do they always occur in labor? Am J Obs Gynecol. 1998;179(4):906-8.

10. Liu L, Antaya R. Neonatal subgaleal hematoma from trauma during vaginal delivery without instrument use. Pediatr Dermatol. 2017;34(1):e40-1.
11. Drapkin Z et al. Is my baby normal? A review of seemingly worrisome but normal newborn signs, symptoms and behaviors. Am J Emerg Med. 2019;37(6):1153-9.

12. Su J. Common rashes in neonates. Aust Fam Physician. 2012;41(5):280-6.

13. van den Berg G, Bakker H. Harlequin color change in a neonate. $\mathrm{N}$ Engl J Med. 2020;382(5):456.

14. Redondo P. Classification of vascular anomalies (tumours and malformations). Clinical characteristics and natural history. An Sist Sanit Navar. 2004;27:Suppl 1:925. (In Spanish).

15. Monteagudo B et al. Salmon patch: a descriptive study. Actas Dermosifiliogr. 2011;102(1):24-7. (In Spanish).

16. Gupta D, Thappa DM. Mongolian spots. Indian J Dermatol Venereol Leprol. 2013;79(4):469-78.

17. Zagne V, Fernandes N. Dermatoses in the first 72 hours of life: a clinical and statistical survey. Indian J Dermatol Venereol Leprol. 2011;77(4):470-6.

18. Pérez-Bescós $L$ et al. Cutaneous hyperpigmentation of the distal phalanges in a newborn infant. An Pediatr (Barc). 2006;65(4):390.

19. Paller A, Mancini A, Hurwitz Clinical Pediatric Dermatology. A Textbook of Skin Disorders of Childhood and Adolescence (2011) $4^{\text {th }}$ edition, Chicago: Elsevier Health Sciences.

20. Eichenfield $L$ et al., Neonatal dermatology (2007) $2^{\text {nd }}$ edition, Philadelphia: Saunders Elsevier Inc.
21. Starace M et al. Nail disorders in children. Skin Appendage Disord. 2018;4(4):217-29.

22. Walker J et al. Koilonychia: an update on pathophysiology, differential diagnosis and clinical relevance. J Eur Acad Dermatol Venereol. 2016;30(11):1985-91.

23. Richert B, André J. Nail disorders in children: diagnosis and management. Am J Clin Dermatol. 2011;12(2):101-12.

24. Morgan AJ et al. Erythema toxicum neonatorum revisited. Cutis. 2009;83(1):13-6.

25. Csoma $Z$ et al. Overview of dermatologic disorders of neonates in a central regional intensive care unit in Hungary. Pediatr Dermatol. 2015;32(2):201-7.

26. Nanda $S$ et al. Analytical study of pustular eruptions in neonates. Pediatr Dermatol. 2002;19(3):210-5.

27. Reginatto FP et al. Benign skin disease with pustules in the newborn An Bras Dermatol. 2016;91(2):124-34.

28. Antaya R, Robinson D. Blisters and pustules in the newborn. Pediatr Ann. 2010;39(10):63-45.

29. Ayhan $M$ et al. Colonization of neonate skin by Malassezia species: relationship with neonatal cephalic pustulosis. J Am Acad Dermatol. 2007;57(6):1012-8.

30. Serna-Tamayo $\mathrm{C}$ et al. Neonatal and infantile acne vulgaris: an update. Cutis. 2014;94(1):13-6.

31. Antoniou $\mathrm{C}$ et al. Clinical and therapeutic approach to childhood acne: an update. Pediatr Dermatol. 2009;26(4):373-80. 
32. Mancini AJ et al. Infantile acropustulosis revisited: history of scabies and response to topical corticosteroids. Pediatr Dermatol. 1998;15(5):337-41.
33. Hernández-Martín Á et al.

Eosinophilic pustular folliculitis of infancy: a series of 15 cases and review of the literature. J Am Acad Dermatol. 2013;68(1):150-5.
34. Fukamachi S et al. Therapeutic effectiveness of various treatments for eosinophilic pustular folliculitis. Acta Derm Venereol. 2009;89(2):155-9. 